\title{
Analysis of Urban Built-Up Expansion Based on Combination of Spectral Indices in Surabaya City
}

\author{
Fendra Dwi Ramadhan*, Teguh Hariyanto, Hepi Hapsari Handayani \\ Department of Geomatics Engineering, FTSPK-ITS, Campus ITS Sukolilo, Surabaya, 60111, Indonesia \\ *Corresponding author: fendra.19033@mhs.its.ac.id
}

Received: 15022021; Revised: 29032021; Accepted: 06082021; Published: 10012022

\begin{abstract}
The urban built-up land indicates the physical changes of the city that represent the development indicator in the city of Surabaya. The expansion of urban built-up land needs to be monitored to control and direct urban areas development. In this study, the identification of urban built-up land was conducted by applying a combination of algorithm-based spectral indices consisting of combination A (UI - NDVI - MNDWI) and combination B (NDBI NDVI - MNDWI) with the spatial expansion analysis that focused on the speed of the urban built-up land expansion and the direction of change of the urban built-up object. Based on the results, the proposed spectral indices combination able to identify the urban built-up land pixels including bare land that free of vegetation and water body object. The pattern of the urban built-up land direction shows a tilt toward the west and east side of the city of Surabaya, while the speed of change shows that combination A and combination B have the same trend, there are a decreasing number of built-up land from 2015 to 2017 and an increasing number of built-up land from 2017 to 2019.
\end{abstract}

Copyright $\odot 2022$ Geoid. All rights reserved.

Keywords: Combination of Spectral Indices; Sentinel-2; Urban Built-up Expansion

How to cite: Ramadhan, F.D., Hariyanto, T., \& Hapsari, H.H. (2021). Analysis of Urban Built-up Expansion Based on Combination of Spectral Indices in Surabaya City. Geoid, 17(1), 21 - 37.

\section{Introduction}

The development indicator on the urban area can be seen from the physical changes, particularly marked by the increase in built-up land. The increase of built-up land is caused by the population and the city center's concentration (Indriastuti et al., 2018). The expansion of built-up land in a city, if not balanced with sufficient land, increases the building density. The continuing density of buildings can cause negative impacts such as a decrease in the quality of settlements and inconsistencies with regional spatial plans (Puspitasari \& Suharyadi, 2016; Izza et al., 2020). The city of Surabaya is the center of trade, government, social, economic, historical, and health activities in East Java Province in Indonesia and its surroundings. The rapid development of the city of Surabaya, triggered by the very high dynamics and activities of the city, demands policies to control and direct urban areas to be more sustainable (KPUPR, 2017). In determining the city's policy, the availability of the data for planning, management, and evaluation is indispensable. Geospatial data as a type of data that capable of informing location, quantity, density, and showing changes, is considered important data in determining urban policy in the city of Surabaya. To analysis, the urban expansion of built-up land, one method that can be used is using multitemporal remote sensing. The multitemporal remote sensing method could see the city's condition based on the parameter and certain focused objects (Prasomsup et al., 2020).

This study aimed to analyze the expansion of the urban built-up land based on the combination of spectral indices. The algorithms of spectral indices that be combined are Urban Index (UI), Normalized Difference Built-up Index (NDBI), Normalized Difference Vegetation Index (NDVI), and Modified Normalized Difference Water Index (MNDWI) that produces pixels only for built-up land that free of vegetation and water body object. The thresholding of every object of the spectral indices is conducted using the Otsu Thresholding method that could separate imagery into binary values that consist of two classes. This method was adapted to simplify the interpretation of the objects based on the spectral indices (built-up, vegetation, and water body) 
(XI et al., 2019). In this study, the expansion's spatial pattern focused on the speed of urban built-up expansion and the direction of the built-up land based on the Standard Deviational Ellipse (Bashit et al., 2020).

\section{Data and Method}

The study area is Surabaya City that located in $7^{\circ} 9^{\prime}-7^{\circ} 21^{\prime} \mathrm{S}$ and $112^{\circ} 36^{\prime}-112^{\circ} 54^{\prime} \mathrm{E}$. Administratively, the city of Surabaya is bordered by the Madura Strait to the north and east, Sidoarjo regency in the south and Gresik regency in the west. The map of the study area is shown in Figure 1. In this study, Sentinel-2 Level-1C imagery that consists of six scenes were used in the year 2015, 2017, and 2019. The validation data that consist of 238 points through Google Earth Imagery was used to perform an accuracy assessment. The software is used includes SNAP, ArcMap 10.8, Microsoft Word, and Microsoft Excel. The dataset of the Sentinel-2 Level$1 \mathrm{C}$ imagery is shown in Table 1.

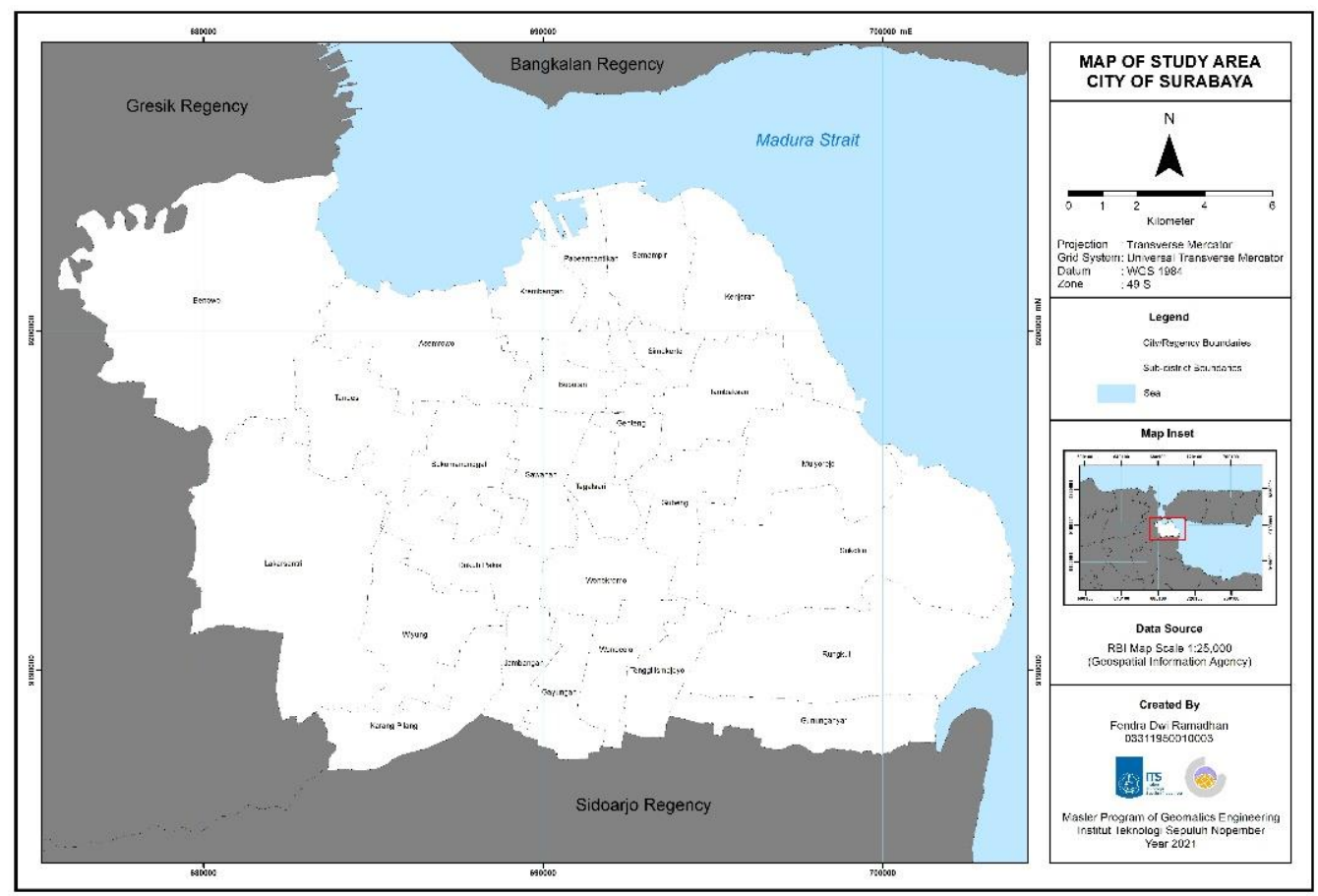

Figure 1. Map of the study area

Table 1 . Imagery dataset

\begin{tabular}{|c|c|c|c|}
\hline Satellite & Cloud cover (\%) & Date of acquisition & Bands used \\
\hline Sentinel-2A & 0.1109 & 7 October 2015 & B2 (Blue) \\
\hline Sentinel-2A & 7.1382 & 24 October 2015 & B3 (Green) \\
\hline Sentinel-2A & 0.0798 & 7 August 2017 & B4 (Red) \\
\hline Sentinel-2B & 0.9043 & 29 August 2017 & B8 (NIR) \\
\hline Sentinel-2B & 0.0114 & 13 July 2019 & B11 (SWIR-1) \\
\hline Sentinel-2A & 1.2783 & 25 July 2019 & B12 (SWIR-2) \\
\hline
\end{tabular}

The data processing of this study is explained based on Figure 2. For the beginning, the preprocessing has been done that consist of atmospheric correction using Sen2Cor 280 plugin that resulted in Sentinel-2 Level-2A with surface reflectance or the bottom of atmosphere (BOA) value for each pixel, and then resampling that resulted in 20-meter spatial resolution for selected bands, mosaicking that resulted in full scene of imagery that covers all the study area, reprojecting that resulted in imagery that has coordinate projection system in WGS 85 UTM Zone $49 \mathrm{~S}$ with the unit in meter and lastly subsetting that resulted in imagery that only covers the study area. 


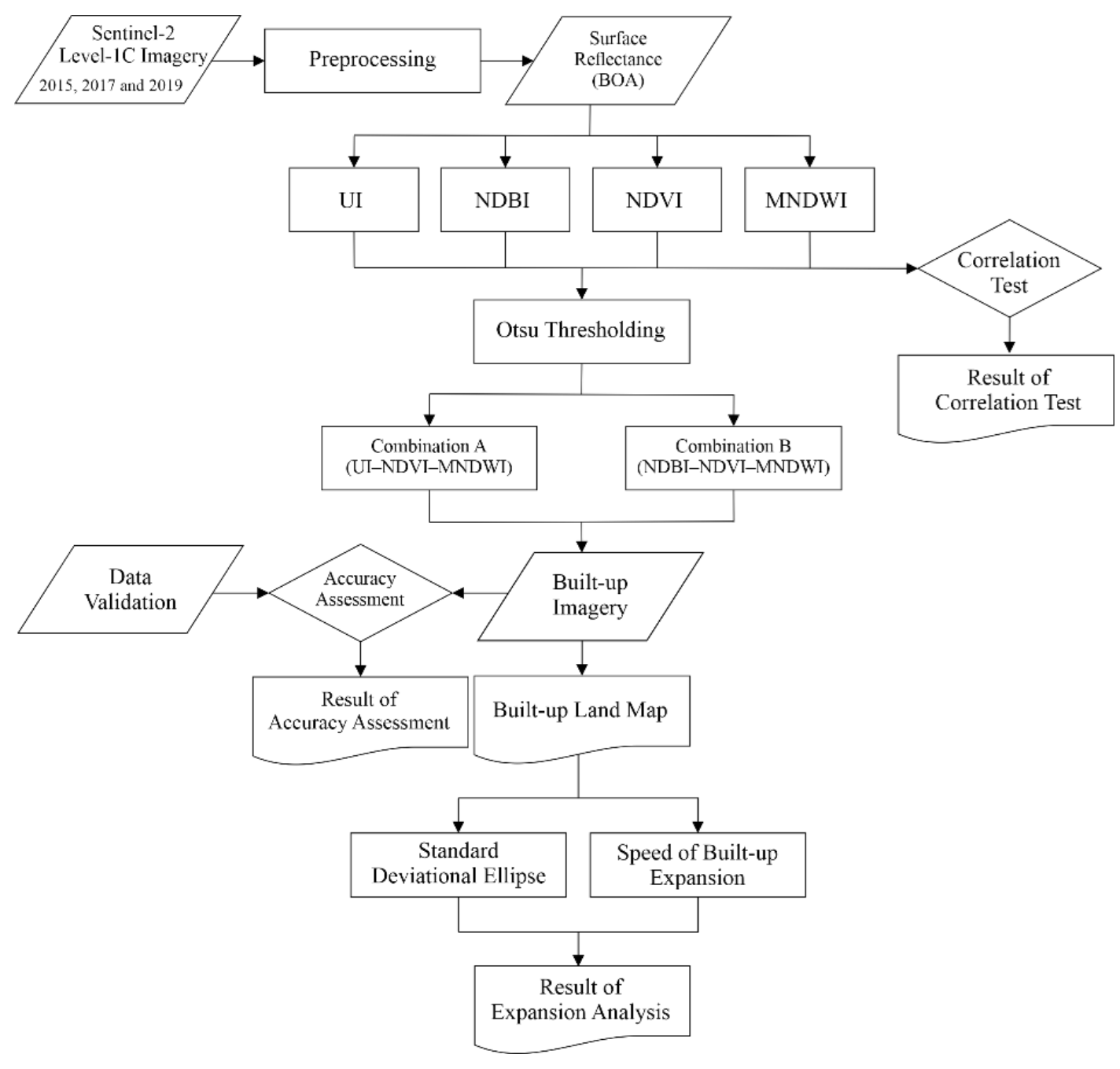

Figure 2. Data processing diagram

The mapping for original-derived built-up land has been conducted based on two spectral indices, namely Urban Index (UI) and Normalized Difference Built-up Index (NDBI). The Urban Index (UI) shows the urban area with higher reflectance in the shortwave infrared spectral range (SWIR-2), while the Normalized Difference Built-up Index (NDBI) highlights the urban area with higher reflectance in the shortwave infrared spectral range (SWIR-1). Both UI and NDBI have a value that varies from -1.0 to +1.0 . Based on XI et al. (2019), the equation for determining UI and NDBI in Sentinel-2 is shown in Equation 1 and Equation 2, respectively.

$U I(x, y)=\frac{\left(\rho_{S W I R-2}(x, y)-\rho_{N I R}(x, y)\right)}{\left(\rho_{S W I R-2}(x, y)+\rho_{N I R}(x, y)\right)}$

(XI et al., 2019)

where,

$U I=$ Urban Index

$\rho_{\text {SWIR-2 }}=$ Surface reflectance of SWIR -2 band

$\rho_{N I R}=$ Surface reflectance of NIR band

$\operatorname{NDBI}(x, y)=\frac{\left(\rho_{S W I R-1}(x, y)-\rho_{N I R}(x, y)\right)}{\left(\rho_{S W I R-1}(x, y)+\rho_{N I R}(x, y)\right)}$

(XI et al., 2019)

where,

$N D B I=$ Normalized Difference Built-up Index

$\rho_{\text {SWIR-1 }}=$ Surface reflectance of SWIR-1 band

$\rho_{\text {NIR }}=$ Surface reflectance of NIR band 
The Normalized Difference Vegetation Index (NDVI) has been used to determine the vegetation object as the vegetation's greenish level. It can calculate based on the B4 (Red) and B8 (NIR) values in the conventional method. Hereinafter, for mapping the water bodies, this study used the Modified Normalized Difference Water Index (MNDWI), which can extract water bodies from satellite imagery. The MNDWI maximizes the water reflectance by using green band wavelength and minimizes the low reflectance of SWIR-1 by absorbing a maximum of wavelength. Both NDVI and MNDWI also have a value ranging from -1.0 to +1.0 . According to XI et al. (2019), the equation for calculating NDVI and MNDWI is shown in Equation 3 and Equation 4, respectively.

$$
\operatorname{NDVI}(x, y)=\frac{\left(\rho_{\text {NIR }}(x, y)-\rho_{\text {Red }}(x, y)\right)}{\left(\rho_{N I R}(x, y)+\rho_{\text {Red }}(x, y)\right)} \quad \text { (XI et al., 2019) }
$$

where,

$N D V I=$ Normalized Difference Vegetation Index

$\rho_{N I R} \quad=$ Surface reflectance of NIR band

$\rho_{\text {Red }} \quad=$ Surface reflectance of Red band

$$
\operatorname{MNDWI}(x, y)=\frac{\left(\rho_{\text {Green }}(\mathrm{x}, \mathrm{y})-\rho_{S W I R-1}(\mathrm{x}, \mathrm{y})\right)}{\left(\rho_{\text {Green }}(\mathrm{x}, \mathrm{y})+\rho_{S W I R-1}(\mathrm{x}, \mathrm{y})\right)} \quad \text { (XI et al., 2019) }
$$

where,

MNDWI = Modified Normalized Difference Water Index

$\rho_{\text {Green }}=$ Surface reflectance of Green band

$\rho_{S W I R-1)}=$ Surface reflectance of SWIR-1 band

The binary thresholding function in ArcMap 10.8 is used to perform the segmentation method, which creates a raster output that divides the raster into two distinct classes. The algorithm behind the Binary Thresholding function, the Otsu method, was developed to distinguish between the background and foreground in imagery by splitting the imagery into two classes with a limited intraclass variance as shown in Figure 3 (Otsu, 1979).
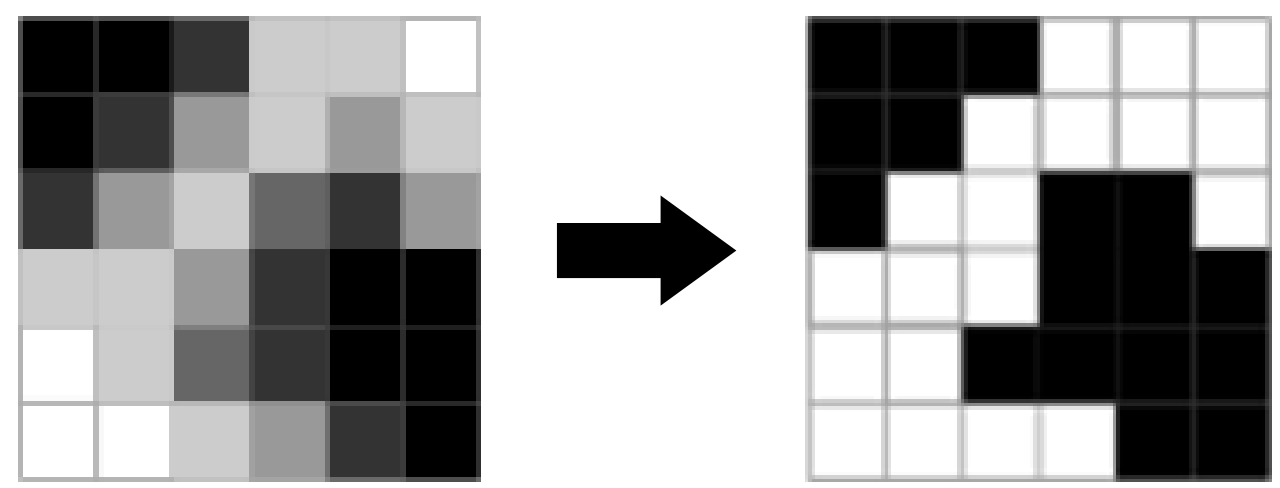

Figure 3. Binary thresholding (Otsu method) (Greensted, 2010)

This study aims to compare the capability of UI and NDBI to extract built-up land which is free of vegetation and water bodies objects using a combination of spectral indices. The calculation has been done by subtracting built-up land indices with vegetation indices and water bodies indices. The combination proposed in this study is shown in Equation 5 and Equation 6, respectively. This combination was adopted from Prasomsup et al. (2020) with modification, which has successfully implemented spectral indices combination with considering vegetation and water bodies parameters.

$$
\begin{array}{lr}
\mathrm{Com}_{A}=U I_{\text {Otsu }}-N D V I_{\text {Otsu }}-M N D W I_{\text {Otsu }} & \text { (Prasomsup et al., 2020) } \\
\text { Com }_{B}=N D B I_{\text {Otsu }}-N D V I_{\text {Otsu }}-M N D W I_{\text {Otsu }} & \text { (Prasomsup et al., 2020) }
\end{array}
$$

where,

$\mathrm{Com}_{A} \quad=$ Built-up land combination A result 


$$
\begin{array}{ll}
\operatorname{Com}_{B} & =\text { Built-up land combination B result } \\
U I_{\text {otsu }} & =\text { UI Otsu Thresholding result } \\
N D B I_{\text {Otsu }} & =\text { NDBI Otsu Thresholding result } \\
N D V I_{\text {Otsu }} & =\text { NDVI Otsu Thresholding result } \\
M N D W I_{\text {Otsu }} & =\text { MNDWI Otsu Thresholding result }
\end{array}
$$

For the spatial expansion analysis, the speed of the built-up expansion method was used to determine the speed change of the built-up in 2015, 2017, and 2019. According to Bashit et al. (2020), the speed of change in builtup land can be formulated based on the average value of built-up land growth as in Equation 7.

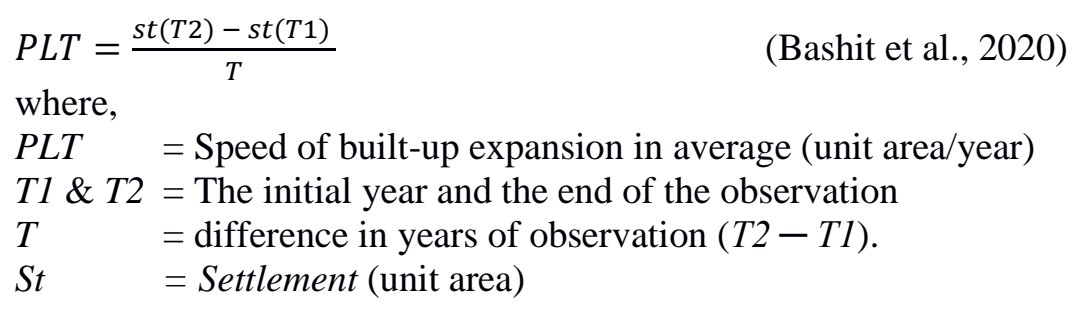

Moreover, to know the direction of change of the built-up object. This study used the standard deviational ellipse method that was calculated using ArcMap 10.8. The Standard Deviational Ellipse is a tool for examining spatial characteristics of geographical features like the inclination center, distribution, and pattern orientation. To evaluate the orientation of the elliptical axis on the function distribution, Standard Deviational Ellipse measures the standard distance in the $\mathrm{x}$ and $\mathrm{y}$ directions. Standard Deviational Ellipse will generate ellipse polygons as new features. The average $\mathrm{x}$ and $\mathrm{y}$ coordinates, two standard distances (long axis and short axis), and ellipse orientation are the ellipse polygon attribute results. The ellipse polygon portrays the difference in direction.

This study's accuracy assessment was conducted using validation data through Google Earth Imagery by creating 238 sample points in the objects that represent the data from Sentinel-2 imagery. The confusion matrix method was adopted to perform accuracy assessments in Microsoft Excel. The result of this assessment was OA (Overall Accuracy) which shows the total calculation of accuracy and Kappa coefficient which explains the simple percentage of agreement calculation.

\section{Results and Discussion}

Based on the result of built-up land mapping using UI and NDBI can be informed in Figure 4 and Figure 5, respectively. Then, the reflectance value of UI and NDBI is shown in Figure 6 and Figure 7, respectively.

Based on Figure 4, it can be informed that by applying Urban Index (UI) calculation using NIR and SWIR-2 bands, the darker brown of the pixel indicates that the more likely it is to be identified as a built-up land, conversely, the lighter brown of the pixel indicates that the more likely it is to be identified as non-built-up land. Furthermore, as seen in Figure 5, by using the NIR and SWIR-1 bands to calculate the Normalized Difference Built-up Index (NDBI), the darker red of the pixel indicates that it is more likely to be classified as a built-up land, while the lighter red of the pixel indicates that it is more likely to be identified as non-built-up land. For UI results, the darker brown pixel means that it has a greater reflectance value than the lighter brown pixel, the same thing for NDBI results, the darker red pixel means that it has a greater reflectance value than the lighter red pixel. Built-up land pixels can be seen in both UI and NDBI in areas that seem to be roofs of buildings, settlements, and housing. While objects included in non-built-up land pixels are seen to be vegetation, parks, water bodies, rice fields, rivers, and ponds. 

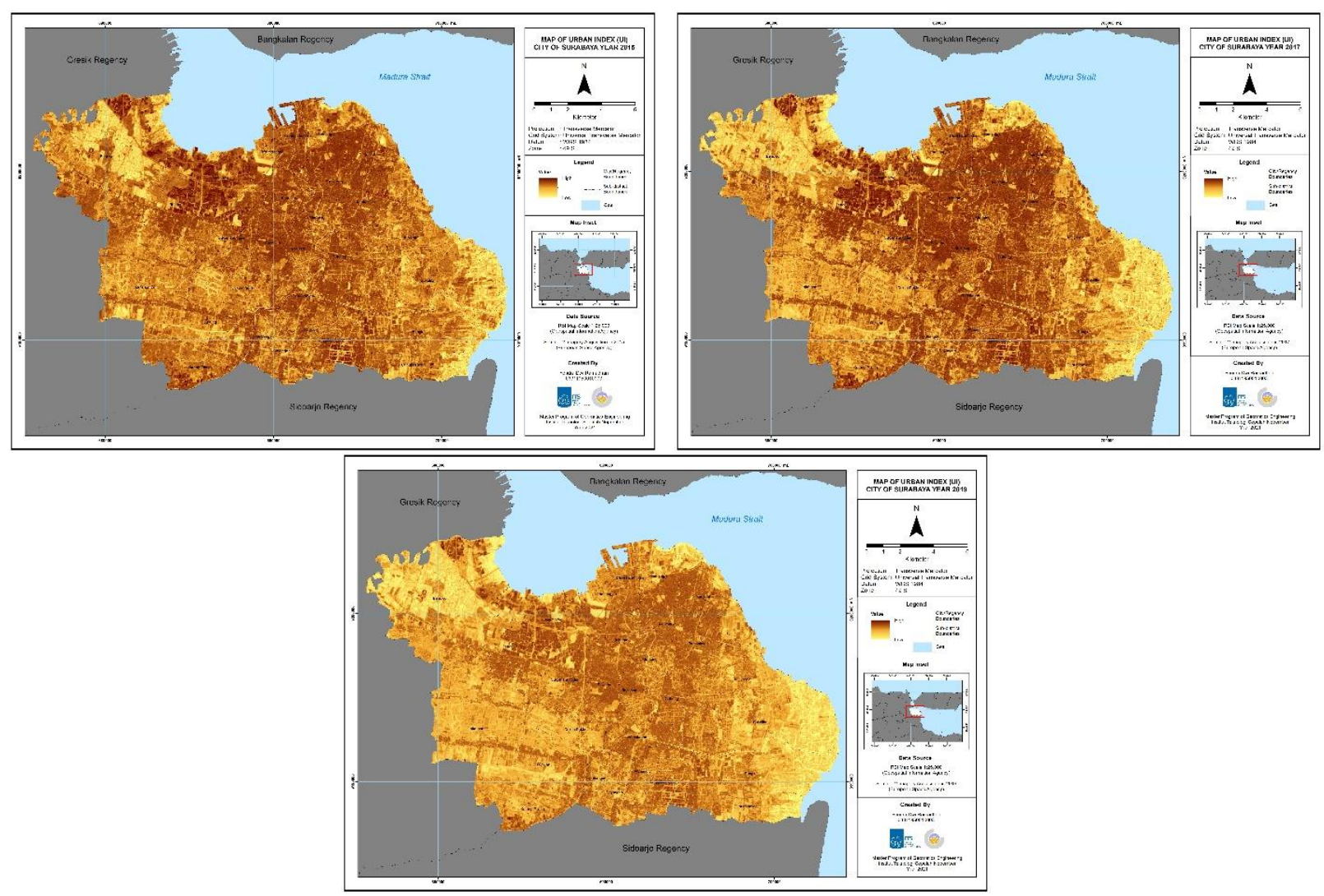

Figure 4. Map of Urban Index (UI)

in 2015, 2017, and 2019 based on clockwise order
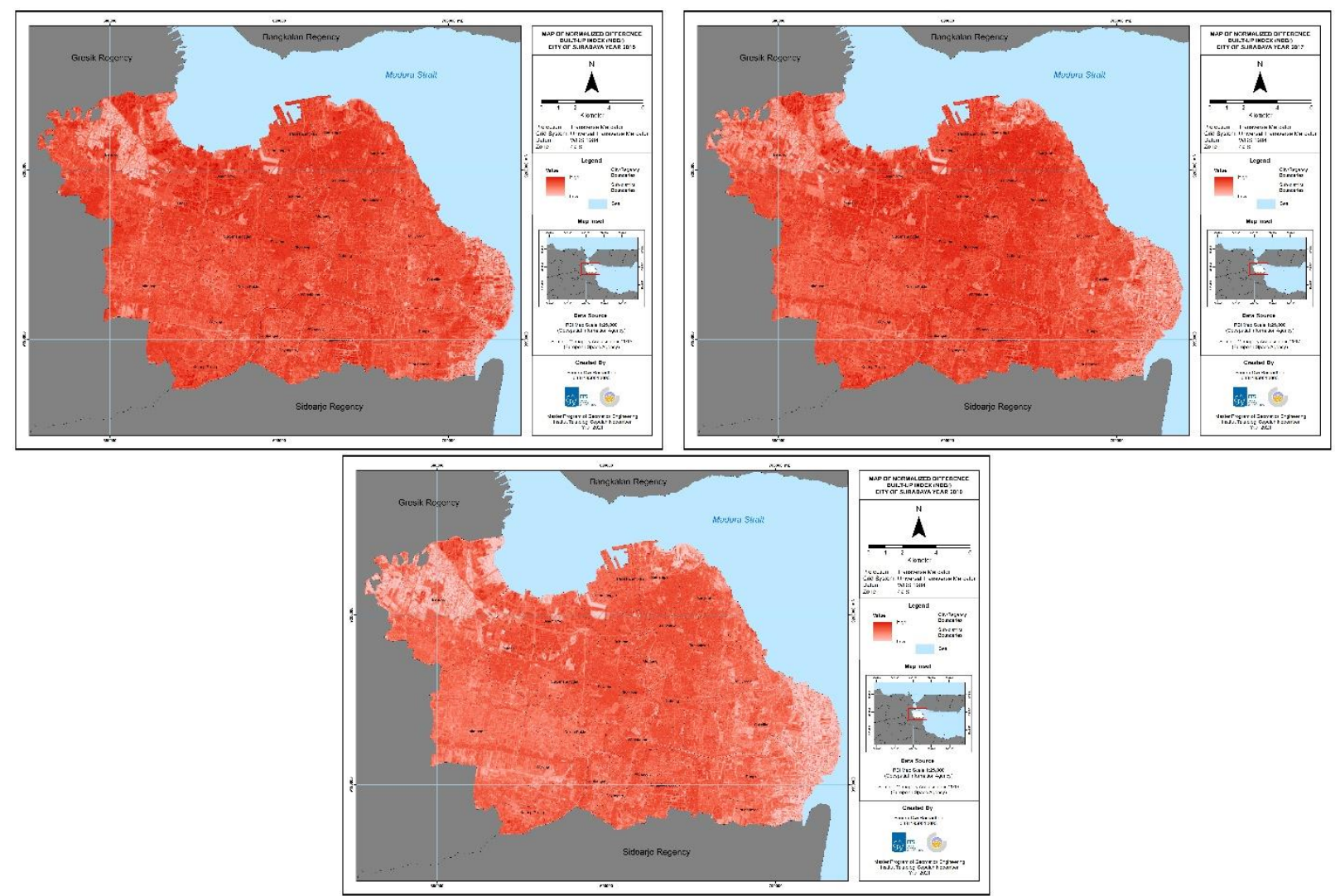

Figure 5. Map of Normalized Difference Built-up Index (NDBI) in 2015, 2017, and 2019 based on clockwise order 


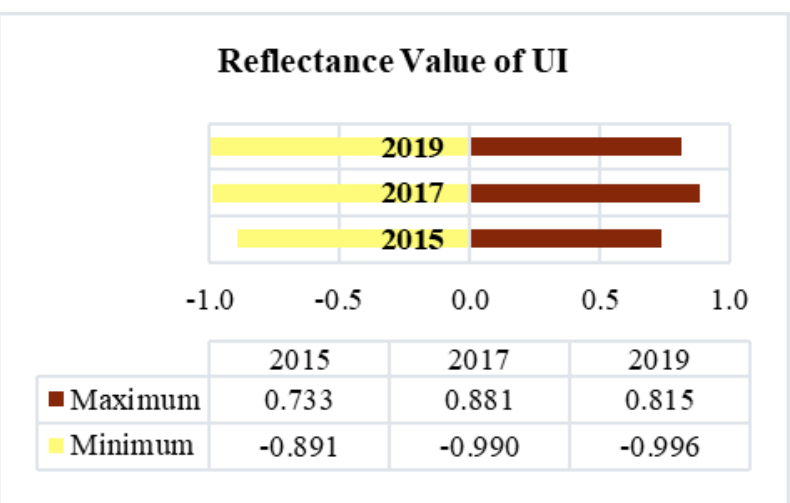

Figure 6. UI reflectance value graph

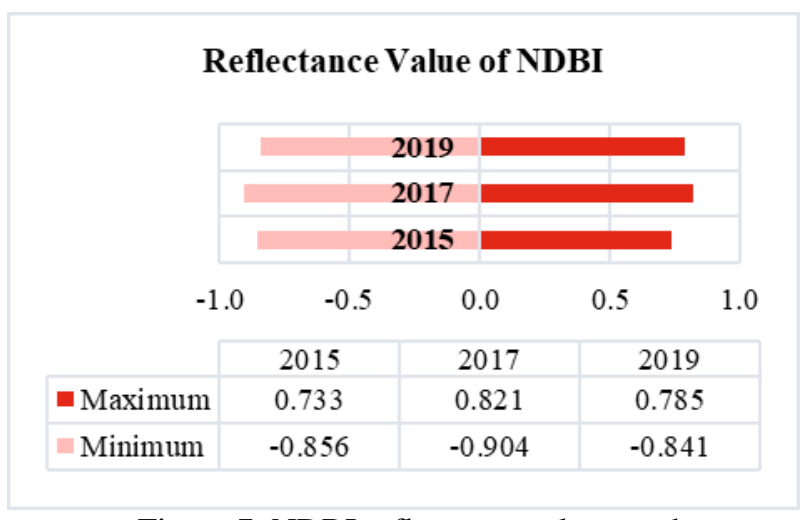

Figure 7. NDBI reflectance value graph

It can be described from Figure 6 that, UI results have the highest (maximum) reflectance value was in 2017 at 0.881 and the lowest (minimum) reflectance value was in 2019 at -0.996 . Then, based on Figure 7, NDBI results have the highest (maximum) reflectance value was in 2017 at 0.821 , and the lowest (minimum) reflectance value was in 2017 at -0.904 . Since the spectral reflectance value for each band used varies and differs in each pixel, the amount of reflectance value generated by the UI and NDBI will be varied throughout the year.

The result of mapping vegetation using NDVI and water bodies using MNDWI can be seen in Figure 8 and Figure 9, respectively. Then, the reflectance value of NDVI and MNDWI are shown in Figure 10 and Figure 11 , respectively
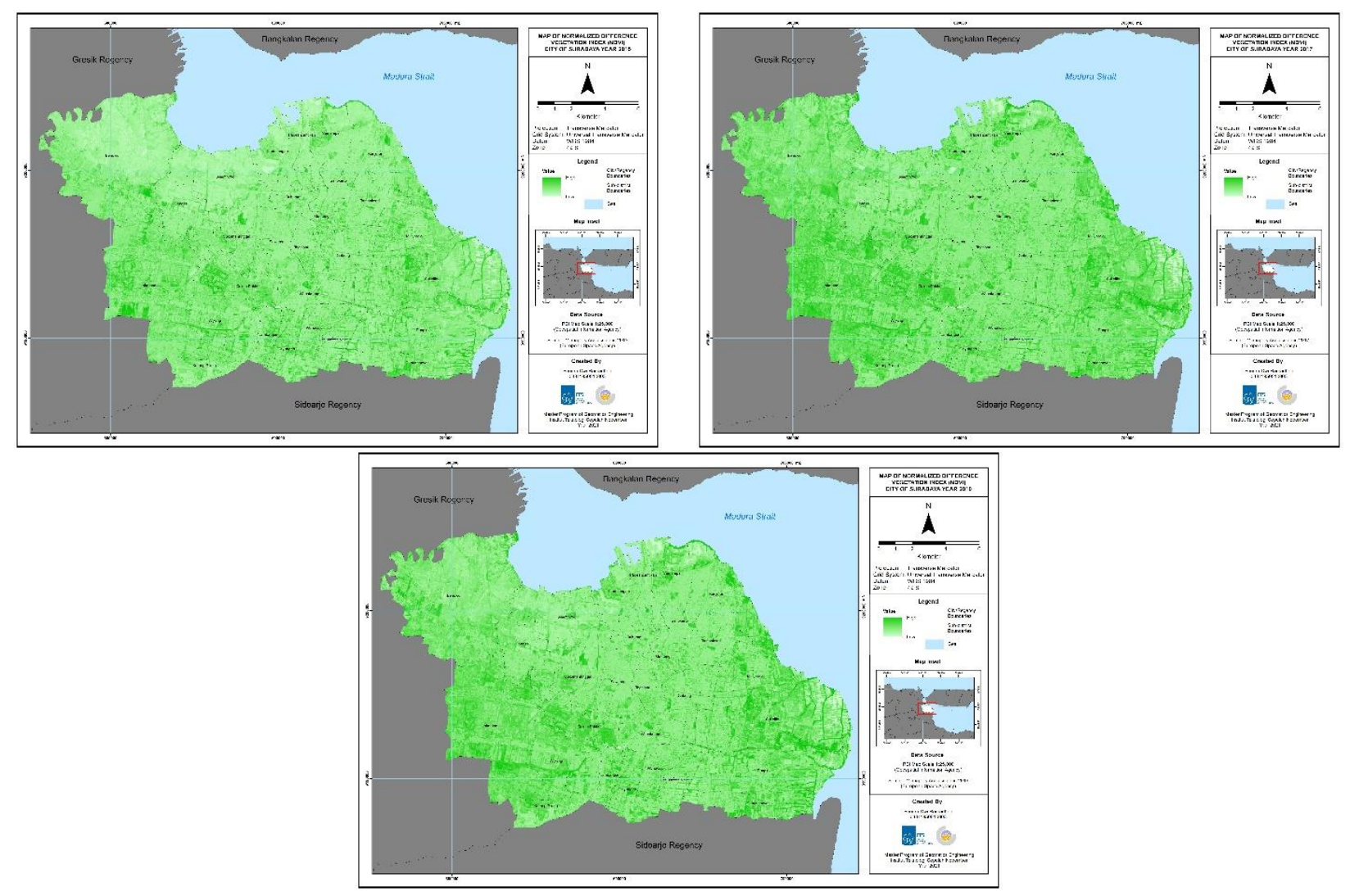

Figure 8. Map of Normalized Difference Vegetation Index (NDVI) in 2015, 2017, and 2019 based on clockwise order 
Based on Figure 8, it can be informed that by applying Normalized Difference Vegetation Index (NDVI) calculation using NIR and Red bands, the darker green of the pixel indicates that the more likely it is to be identified as vegetation, conversely, the lighter green of the pixel indicates that the more likely it is to be identified as non-vegetation. Furthermore, as seen in Figure 9, by using the Green and SWIR-1 bands to calculate the Modified Normalized Difference Water Index (MNDWI), the darker blue of the pixel indicates that it is more likely to be classified as water bodies, while the lighter blue of the pixel indicates that it is more likely to be identified as non-water bodies. Same as UI dan NDBI, for NDVI results, the darker green pixel means that it has a greater reflectance value than the lighter green pixel, while for MNDWI results, the darker blue pixel means that it has a greater reflectance value than the lighter blue pixel.
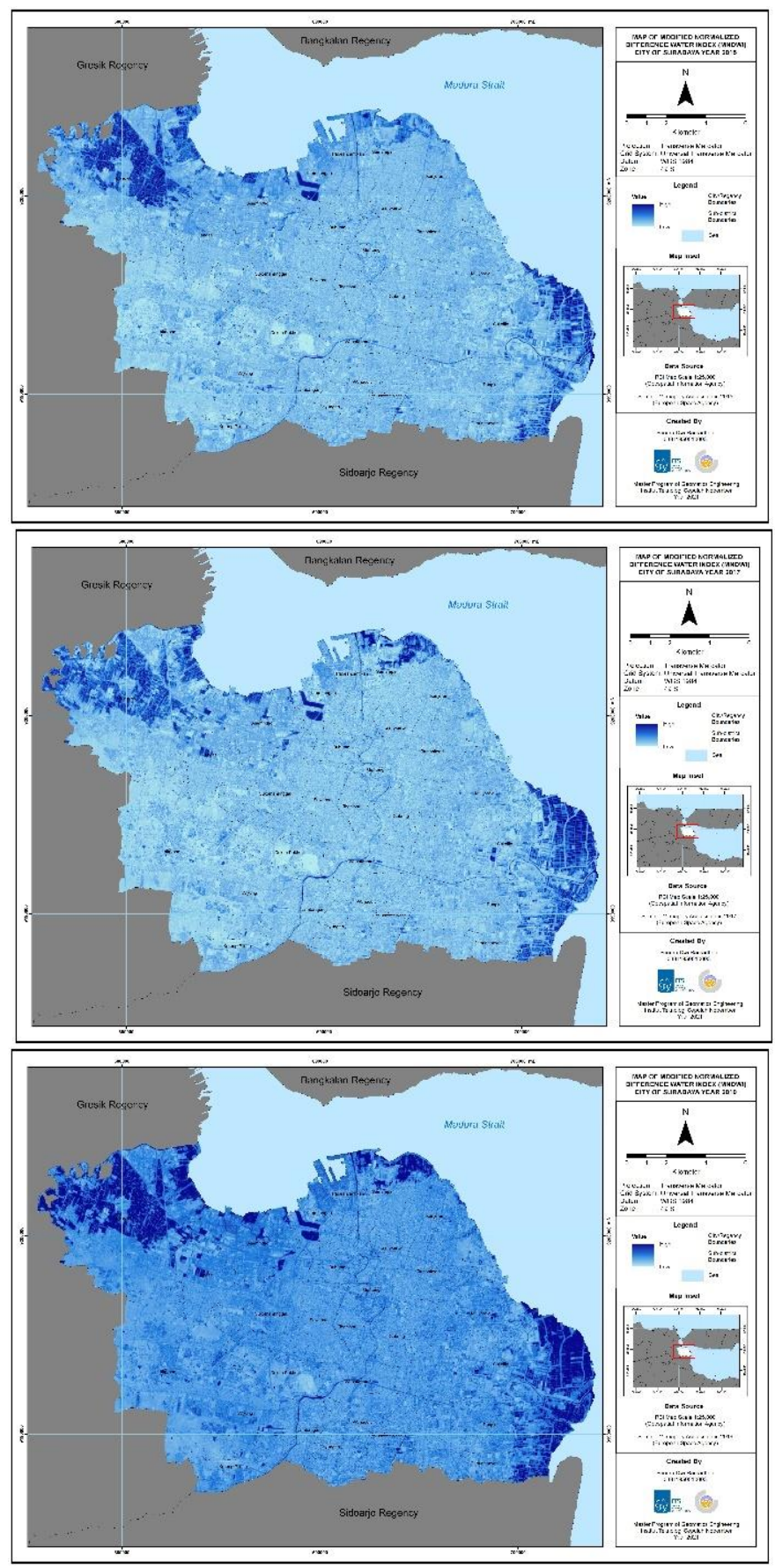

Figure 9. Map of Modified Normalized Difference Water Index (MNDWI) in 2015, 2017, and 2019 


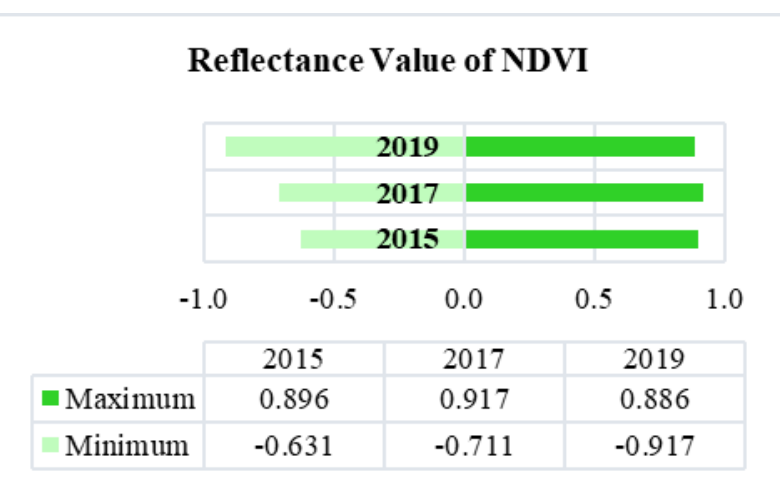

Figure 10. NDVI reflectance value graph

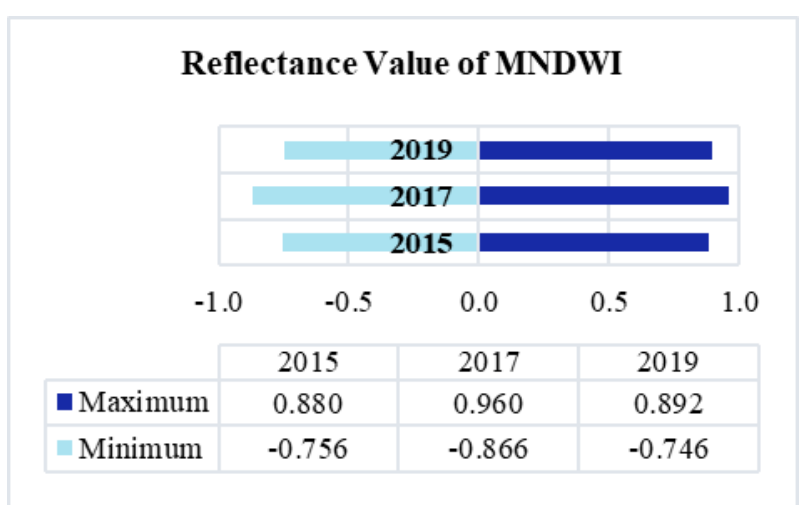

Figure 11. MNDWI reflectance value graph

It can be informed from Figure 10 that, NDVI results have the highest (maximum) reflectance value was in 2017 at 0.917 and the lowest (minimum) reflectance value was in 2019 at -0.917 . Then, based on Figure 11, MNDWI results have the highest (maximum) reflectance value was in 2017 at 0.960 , and the lowest (minimum) reflectance value was in 2017 at -0.866 . Same as UI and NDBI, the amount of reflectance value generated by NDVI and MNDWI varies throughout the year, this occurs due to the spectral reflectance value for each band used is varies and differs for each pixel.

The correlation between each index can be obtained and seen in Table 2 by extracting the reflectance value from each index using 238 points distributed randomly in the study area based on the Stratified Random Sampling method.

Table 2. Correlation matrix between spectral indices

\begin{tabular}{|c|c|c|c|c|c|c|c|c|c|c|c|c|c|c|}
\hline \multicolumn{5}{|c|}{2015} & \multicolumn{5}{|c|}{2017} & \multicolumn{5}{|c|}{2019} \\
\hline & UI & $\begin{array}{c}\text { ND } \\
\text { BI }\end{array}$ & $\begin{array}{l}\text { ND } \\
\text { VI }\end{array}$ & $\begin{array}{l}\text { MND } \\
\text { WI }\end{array}$ & & UI & $\begin{array}{c}\text { ND } \\
\text { BI }\end{array}$ & $\begin{array}{l}\text { ND } \\
\text { VI }\end{array}$ & $\begin{array}{l}\text { MND } \\
\text { WI }\end{array}$ & & UI & $\begin{array}{c}\text { ND } \\
\text { BI }\end{array}$ & $\begin{array}{l}\text { ND } \\
\text { VI }\end{array}$ & $\begin{array}{c}\text { MND } \\
\text { WI }\end{array}$ \\
\hline UI & $\begin{array}{c}1.00 \\
0\end{array}$ & $\begin{array}{c}0.94 \\
7\end{array}$ & $\begin{array}{c}- \\
0.53 \\
6 \\
\end{array}$ & $\begin{array}{c}- \\
0.397\end{array}$ & UI & $\begin{array}{c}1.00 \\
0\end{array}$ & $\begin{array}{c}0.95 \\
5\end{array}$ & $\begin{array}{c}- \\
0.42 \\
6 \\
\end{array}$ & $\begin{array}{c}- \\
0.584\end{array}$ & UI & $\begin{array}{c}1.00 \\
0\end{array}$ & $\begin{array}{c}0.96 \\
7\end{array}$ & $\begin{array}{c}- \\
0.47 \\
3 \\
\end{array}$ & $\begin{array}{c}- \\
0.599\end{array}$ \\
\hline NDBI & $\begin{array}{c}0.94 \\
7\end{array}$ & $\begin{array}{c}1.00 \\
0\end{array}$ & $\begin{array}{c}- \\
0.43 \\
4\end{array}$ & $\begin{array}{c}- \\
0.507\end{array}$ & NDBI & $\begin{array}{c}0.95 \\
5\end{array}$ & $\begin{array}{c}1.00 \\
0\end{array}$ & $\begin{array}{c}- \\
0.30 \\
4\end{array}$ & $\begin{array}{c}- \\
0.693\end{array}$ & NDBI & $\begin{array}{c}0.96 \\
7\end{array}$ & $\begin{array}{c}1.00 \\
0\end{array}$ & $\begin{array}{c}- \\
0.37 \\
4\end{array}$ & $\begin{array}{c}- \\
0.689\end{array}$ \\
\hline NDVI & $\begin{array}{c}- \\
0.53 \\
6\end{array}$ & $\begin{array}{c}- \\
0.43 \\
4\end{array}$ & $\begin{array}{c}1.00 \\
0\end{array}$ & $\begin{array}{c}- \\
0.514\end{array}$ & NDVI & $\begin{array}{c}- \\
0.42 \\
6\end{array}$ & $\begin{array}{c}0.30 \\
4 \\
\end{array}$ & $\begin{array}{c}1.00 \\
0\end{array}$ & $\begin{array}{c}- \\
0.434\end{array}$ & NDVI & $\begin{array}{c}- \\
0.47 \\
3\end{array}$ & $\begin{array}{c}- \\
0.37 \\
4\end{array}$ & $\begin{array}{c}1.00 \\
0\end{array}$ & $\begin{array}{c}- \\
0.382\end{array}$ \\
\hline $\begin{array}{c}\text { MND } \\
\text { WI }\end{array}$ & $\begin{array}{c}- \\
0.39 \\
7\end{array}$ & $\begin{array}{c}- \\
0.50 \\
7\end{array}$ & $\begin{array}{c}- \\
0.51 \\
4\end{array}$ & 1.000 & $\begin{array}{c}\text { MND } \\
\text { WI }\end{array}$ & $\begin{array}{c}- \\
0.58 \\
4\end{array}$ & $\begin{array}{c}- \\
0.69 \\
3\end{array}$ & $\begin{array}{c}- \\
0.43 \\
4\end{array}$ & 1.000 & $\begin{array}{c}\text { MND } \\
\text { WI }\end{array}$ & $\begin{array}{c}- \\
0.59 \\
9\end{array}$ & $\begin{array}{c}- \\
0.68 \\
9\end{array}$ & $\begin{array}{c}- \\
0.38 \\
2\end{array}$ & 1.000 \\
\hline
\end{tabular}

Based on Table 2, it can be seen that the UI and NDBI spectral indices have a positive relationship of 0.947 in 2015, 0.955 in 2017, and 0.967 in 2019, so they can be categorized as having a very high correlation (a very reliable relationship). Each high UI reflectance value will be followed by the NDBI reflectance value. On the other hand, if the UI reflectance value is low, the NDBI reflectance value will also be followed, which means that UI and NDBI having linear spectral indices with the same pattern. The similarity of the identified objects, namely as a built-up land, explains the positive relationship between the UI and NDBI spectral indices.

Whereas, the relationship is also formed with other spectral indices. According to Table 2, the UI and NDBI had a negative relationship with the NDVI and MNDWI in 2015, 2017, and 2019. This is quite understandable with the assumption that, if the reflectance value of UI and NDBI is high (indicating the built-up land), it means that the reflectance value of NDVI (indicating the vegetation object) and MNDWI (indicating water bodies object) will be low and even negative, which means that if an area is identified as a built-up land object (extracted by UI and NDBI), the area has little or no vegetation and water bodies object. Therefore, the 
correlation between UI and NDBI to NDVI and MNDWI can be categorized as low to moderate negative correlation.

This assumption may not be interpreted in general and it has to be assessed in the future because not all the study area has the same characteristic of reflectance value like in Surabaya. For example, if there is a green roof of the building, which can be interpreted as a vegetation object even it's located in the built-up land, in this case, it is a building, it may confuse UI, NDBI, and NDVI algorithm. On the other hand, if there is no vegetation on the roof of the building, it ideally will interpret as built-up land. So, as the condition of Surabaya itself, it can be expected that if the low to moderate negative correlation between UI and NDBI to NDVI and MNDWI is caused by the reflectance process.

Table 2 also indicates that the relationship between the NDVI and MNDWI had a negative correlation value in 2015, 2017, and 2019, which means that if the NDVI reflectance value is positive, the MNDWI reflectance value will be negative in this case, if an area is identified as a vegetation object, then the area is not water bodies object. Therefore, the correlation between NDVI and MNDWI can be categorized as a low to moderate negative correlation.

The binary thresholding function in ArcMap 10.8, which is based on the otsu thresholding method, is used to process the object segmentation. At the end of the segmentation process, as seen in Figure 11, several raster imageries that have a binary value ( 0 and 1$)$ are produced, so that only two classes of objects have resulted. The value 1 represents the object identified, and the value 0 represents not the object identified. It can be seen that the pixel of built-up land and non-built-up land can be identified from UI and NDBI, the pixel of vegetation and non-vegetation can be identified from NDVI, and the pixel of water bodies and non-water bodies can be identified from MNDWI.
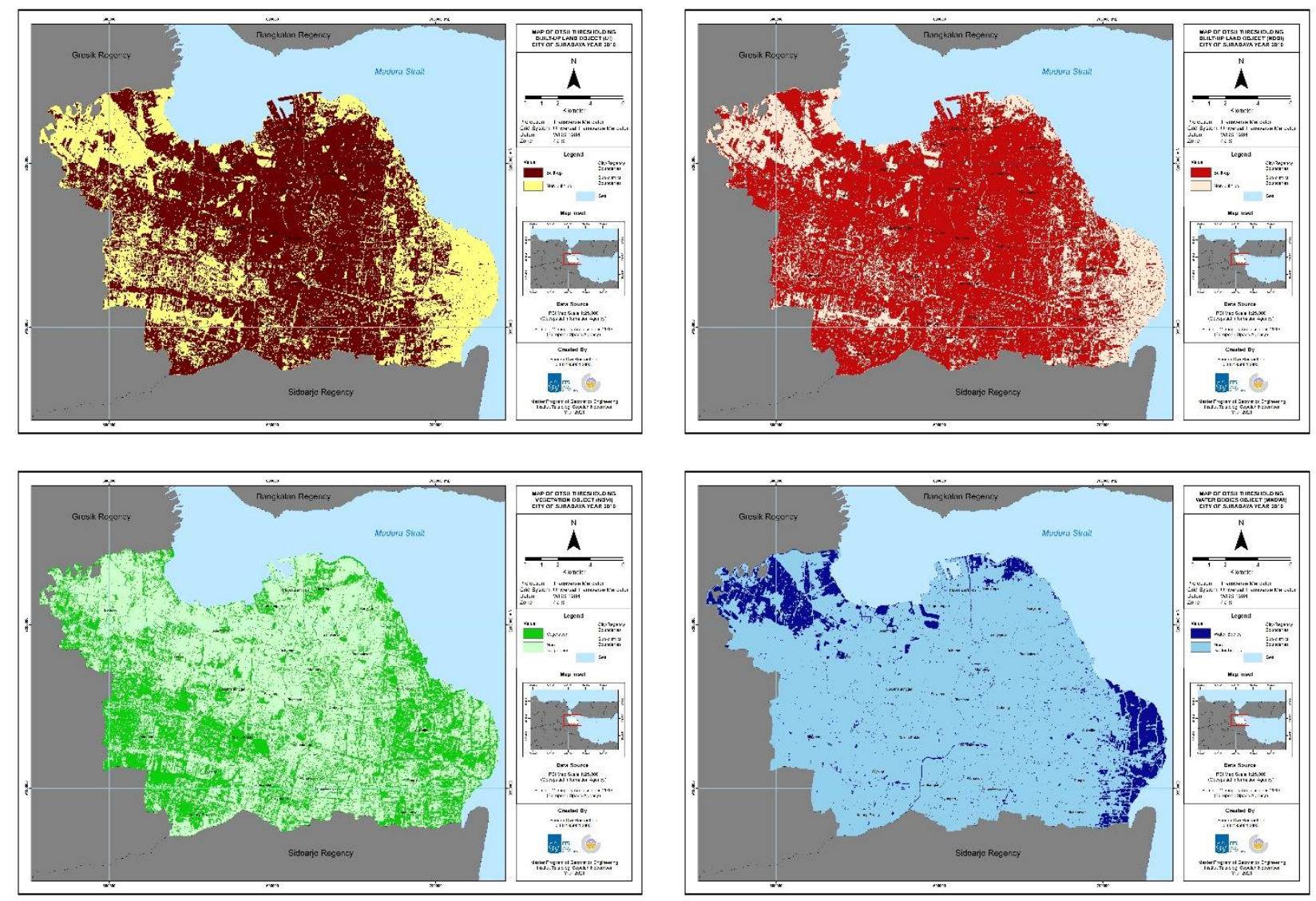

Figure 12. Map of otsu thresholding for each spectral indices (UI, NDBI, NDVI, and MNDWI) in 2019 based on clockwise order 
As seen in Figure 13, two spectral indices combinations were produced in this study: Combination A (UI NDVI MNDWI) and combination B (NDBI NDVI MNDWI). The calculation is done by subtracting the pixel object from each spectral indices.

Combination A assumes that the areas identified as the built-up land object from the UI index result are subtracted from the areas identified as vegetation object from the NDVI index result and the areas identified as water bodies object from the MNDWI index result. In comparison, combination B assumes that the area identified as a built-up land object from the NDBI index result is subtracted from the area identified as a vegetation object from the NDVI index result and the area identified as a water body object from the MNDWI index result. The results obtained from these two combinations are raster imageries in the form of built-up land pixels (UI and NDBI), which are free from vegetation object pixels (NDVI) and water bodies object pixels (MNDWI). The land cover class is divided into two, namely built-up land, which has a pixel value of 1, and non-built-up land, which has a pixel value of 0 .

2015
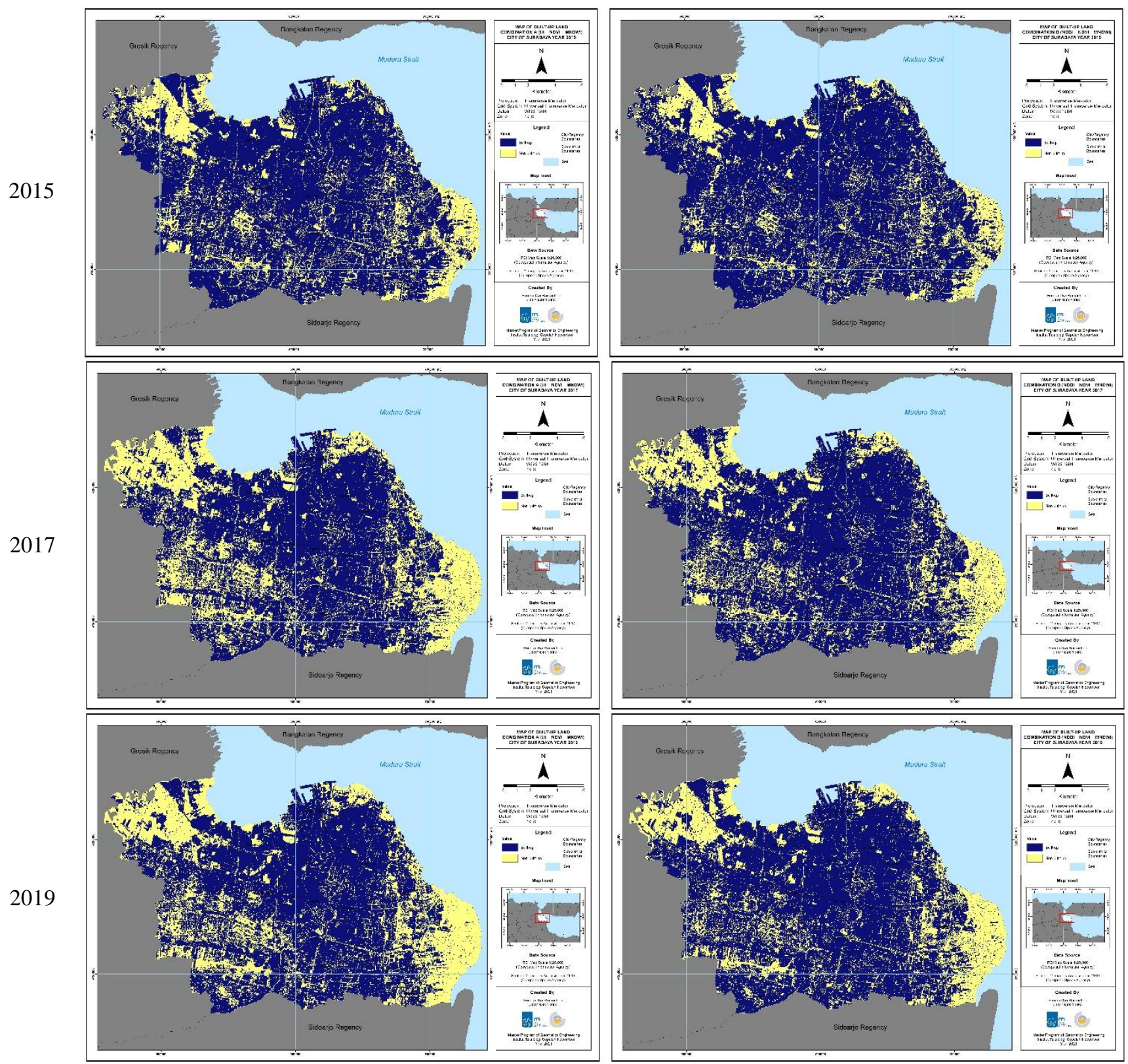

Combination A (UI NDVI MNDWI)

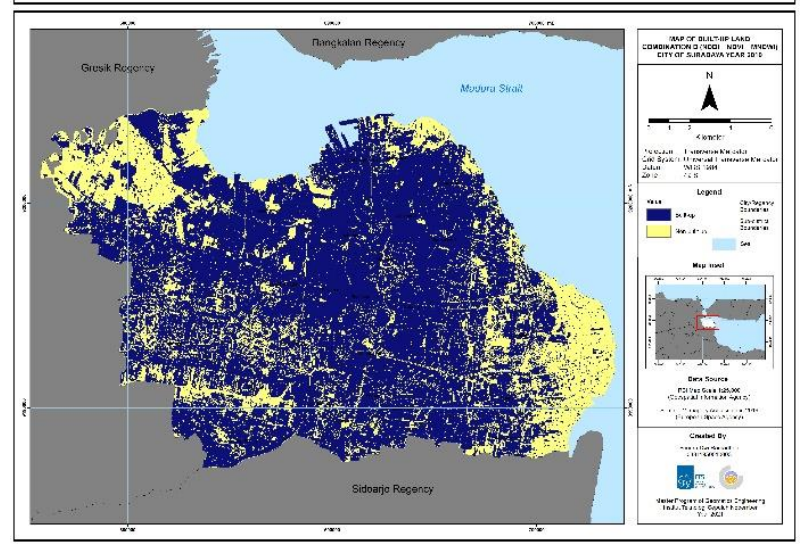

Combination B (NDBI NDVI MNDWI)

Figure 13. Map of built-up land combination A and combination B in 2015, 2017, and 2019 
As the results from the calculation shown in Table 3 for combination A, the largest built-up land cover class was in 2015 at $245.3416 \mathrm{~km}^{2}(74.7 \%)$, while the lowest built-up land cover class was in 2017 at $215.5584 \mathrm{~km}^{2}$ (65.6\%). Meanwhile, as the results from the calculation shown in Table 4 for combination B, the largest builtup land cover class was in 2015 at $252.7820 \mathrm{~km}^{2}$ (76.9\%), while the lowest built-up land cover class was in 2017 at $233.7552 \mathrm{~km}^{2}(71.1 \%)$.

Table 3. Comparison of area and counts of land cover from Combination A result

\begin{tabular}{ccccccc}
\hline \multirow{2}{*}{ Land Cover } & \multicolumn{3}{c}{ Area $\left(\mathrm{km}^{2}\right)$ and Percentage (\%) } & \multicolumn{3}{c}{ Count and Percentage (\%) } \\
\cline { 2 - 7 } & 2015 & 2017 & 2019 & 2015 & 2017 & 2019 \\
\hline \multirow{2}{*}{ Built-up } & 245.3416 & 215.5584 & 217.4776 & 613354 & 538896 & 543694 \\
& $(74.7 \%)$ & $(65.6 \%)$ & $(66.2 \%)$ & $(74.7 \%)$ & $(65.6 \%)$ & $(66.2 \%)$ \\
\hline \multirow{2}{*}{ Non-built-up } & 83.2200 & 113.0032 & 111.084 & 208050 & 282508 & 277710 \\
& $(25.3 \%)$ & $(34.4 \%)$ & $(33.8 \%)$ & $(25.3 \%)$ & $(34.4 \%)$ & $(33.8 \%)$ \\
\hline \multirow{2}{*}{ Total } & & 328.5616 & & & 821404 & \\
& & $(100 \%)$ & & & $(100 \%)$ & \\
\hline
\end{tabular}

Table 4. Comparison of area and counts of land cover from Combination B result

\begin{tabular}{ccccccc}
\hline \multirow{2}{*}{ Land Cover } & \multicolumn{3}{c}{ Area $\left(\mathrm{km}^{2}\right)$ and Percentage (\%) } & \multicolumn{3}{c}{ Count and Percentage (\%) } \\
\cline { 2 - 7 } & 2015 & 2017 & 2019 & 2015 & 2017 & 2019 \\
\hline \multirow{2}{*}{ Built-up } & 252.7820 & 233.7552 & 234.0156 & 631955 & 584388 & 585039 \\
& $(76.9 \%)$ & $(71,1 \%)$ & $(71,2 \%)$ & $(76.9 \%)$ & $(71.1 \%)$ & $(71.2 \%)$ \\
\hline \multirow{2}{*}{ Non-built-up } & 75.7796 & 94.8064 & 94.5460 & 189449 & 237016 & 236365 \\
& $(23.1 \%)$ & $(28.9 \%)$ & $(28.8 \%)$ & $(23.1 \%)$ & $(28.9 \%)$ & $(28.8 \%)$ \\
\hline \multirow{2}{*}{ Total } & & 328.5616 & & & 821404 & \\
& & $(100 \%)$ & & & $(100 \%)$ & \\
\hline
\end{tabular}
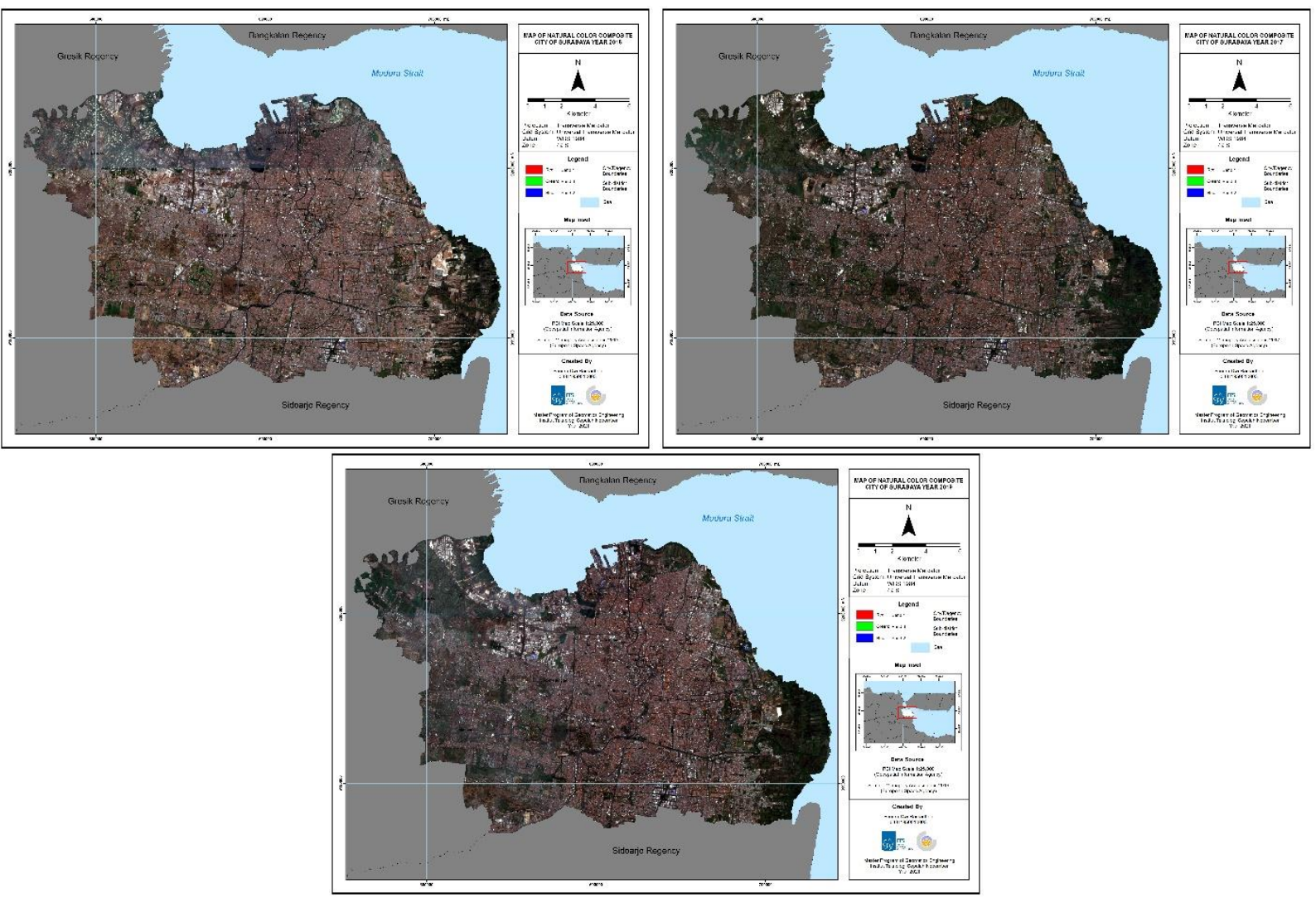

Figure 14. Map of natural color composite in 2015, 2017, and 2019 based on clockwise order 
When viewed from the resulting area, it can be seen that both combinations $\mathrm{A}$ and $\mathrm{B}$ have a significant value in 2015, as compared to 2017 and 2019. In 2015, there are a few land covers in the city of Surabaya in the form of bare land, as shown in the natural color appearance of Sentinel-2 imagery in Figure 14. In this study, the results of combination A and combination B show that bare land objects are considered as built-up land objects, whereas water bodies and vegetation can be differentiated into non-built-up objects. This is clarified in the following Figure 15.

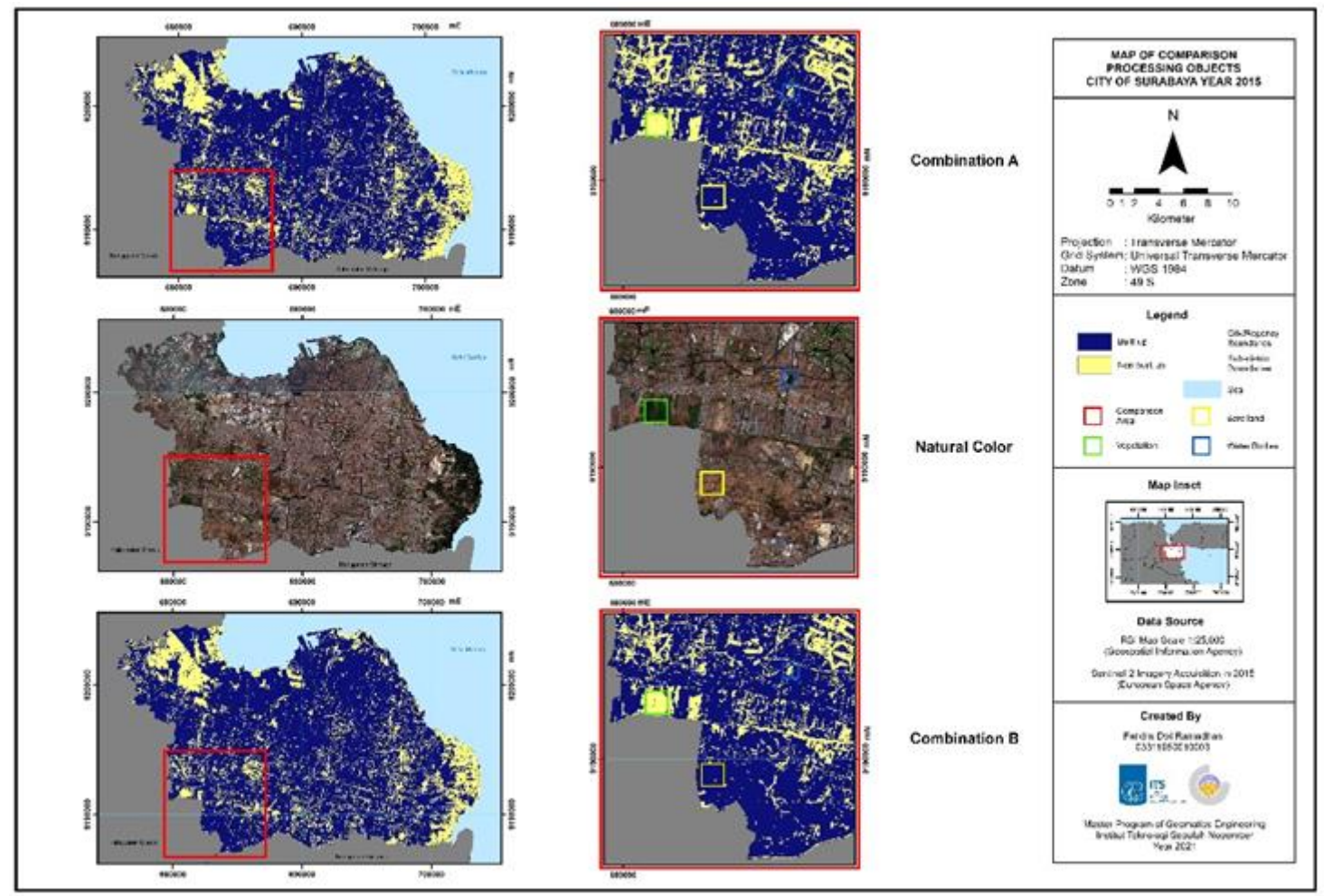

Figure 15. Comparison of processing objects

In this study, an accuracy assessment using a minimum of 238 test point samples is needed that is evenly distributed in the city of Surabaya and based on the Stratified Random Sampling method, which determines several sample points that are randomly distributed in each class, where each class has several points that are proportional to its relative area. The Kappa coefficient shows the level of agreement strength between the classified data and the referenced data from Google Earth Imagery. While overall accuracy (OA) is calculated as the total number of correctly classified pixels divided by the total number of test pixels (Congalton \& Green, 2009).

Based on accuracy assessment results that have been carried out, it can be summarized that the values of Kappa coefficient and overall accuracy (OA) in the combination method of spectral indices are categorized into the medium to high level or have agreement strength at moderate to a high level. As shown in Table 5, the following shows a summary of the overall accuracy $(\mathrm{OA})$ and Kappa coefficient values from all methods.

Table 5. Overall accuracy (OA) and Kappa coefficient values results

\begin{tabular}{cccccccc}
\hline Methods & \multicolumn{2}{c}{2015} & \multicolumn{2}{c}{2017} & \multicolumn{2}{c}{2019} & Interpretation of \\
\cline { 1 - 7 } Parameter & OA & Kappa & OA & Kappa & OA & Kappa & Kappa value \\
\hline Combination A & $87 \%$ & 0.692 & $90 \%$ & 0.778 & $92 \%$ & 0.815 & Medium - High \\
\hline Combination B & $83 \%$ & 0.605 & $87 \%$ & 0.702 & $90 \%$ & 0.771 & Medium - High \\
\hline
\end{tabular}

Because the two methods have a minimum Kappa coefficient value which is included in the medium category, it can be said that the processing results are acceptable and sufficient to represent the actual condition of the object. However, in this study, for further spatial expansion analysis, processing will only use the results of 
the combination of the spectral index, namely combination A and combination B, because it uses parameters with Kappa interpretation values that are in the best category, namely moderate to a high level.

The spatial expansion analysis consists of the calculation of the speed of the urban built-up land expansion and shown in Table 6, Table 7, and the directional pattern of the built-up land as seen in Figure 16.
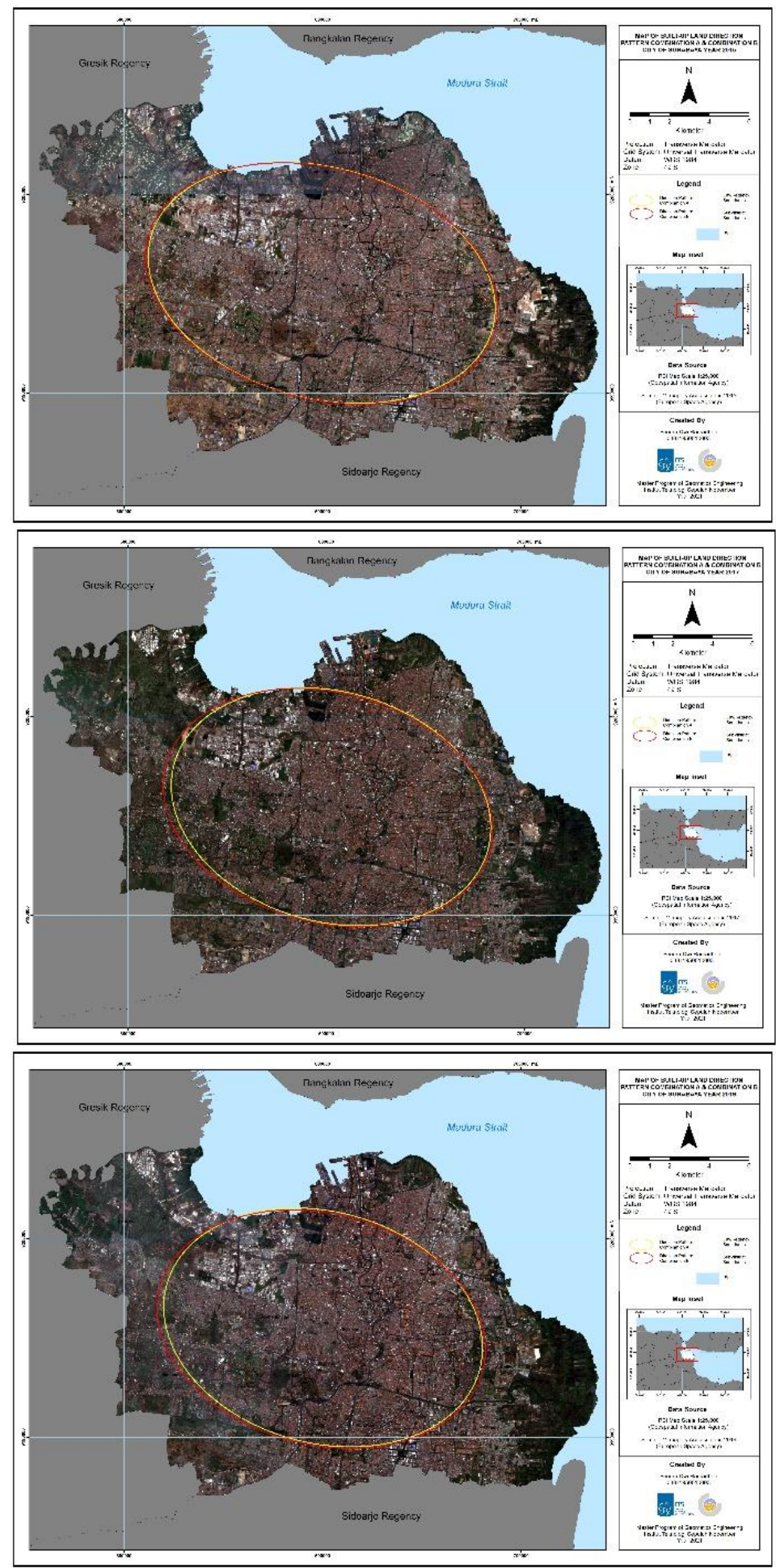

Figure 16. Map of built-up direction pattern based on clockwise order in 2015, 2017 and 2019 
It can be seen from Figure 16 that the ellipse inclination is leaning northwest on the left ellipse and southeast on the right side of the ellipse. This explains that the changes in the direction pattern of built-up in 2015, 2017, and 2019 periods are towards the west and east sides of Surabaya City. This is acceptable because, on the north side, the city of Surabaya borders the Madura Strait. It is not possible to develop built-up land in the area, while on the south side bordering Sidoarjo Regency, the development of built-up land may also occur in that area. On the west side, the development of built-up land may occur up to the border with Gresik Regency, while the development of built-up land on the eastern side is limited to the Surabaya City coastline.

Based on the calculation of the speed of area change, in Table 6 for combination A, it is found that from 2015 to 2017, there was a decrease in the area of built-up land by $29.783 \mathrm{~km}^{2}$ with a change in area speed of 14.892 $\mathrm{km} 2 /$ year, in 2017 to 2019 it occurred an increase in the area of built-up land by $1.919 \mathrm{~km}^{2}$ with a change in area speed of $0.960 \mathrm{~km}^{2} /$ year. In accumulation from 2015 to 2019 , there was a decrease in the area of built-up land by $27.864 \mathrm{~km}^{2}$ with a change in area speed of $6.966 \mathrm{~km}^{2} /$ year.

Meanwhile, based on Table 7 for combination B, it is found that in 2015 to 2017, there was a decrease in the area of built-up land by $19.027 \mathrm{~km}^{2}$ with a speed of change in the area of $9.513 \mathrm{~km}^{2} /$ year, from 2017 to 2019 there was an increase in the area of built-up land by $0.260 \mathrm{~km}^{2}$ with a change in area speed of $0.130 \mathrm{~km}^{2} / \mathrm{year}$. In accumulation from 2015 to 2019 , there has been a decrease in the area of built-up land by $18.766 \mathrm{~km}^{2}$ with a speed of change in the area of $4.692 \mathrm{~km}^{2} /$ year. The calculation of the speed of change in the area of built-up land for both combination A and combination B is also affected by misidentification on the bare land area. This means that the bare land area is included as a built-up object. The sign (+) and (-) in Table 6 and Table 7 indicates the increase and decrease in land cover area, respectively.

Table 6. Comparison of area and speed of change in the area of the land cover result of Combination A

\begin{tabular}{ccccccc}
\hline \multirow{2}{*}{ Land Cover } & \multicolumn{3}{c}{ Area Change $\left(\mathrm{km}^{2}\right)$} & \multicolumn{3}{c}{ Speed of area change $\left(\mathrm{km}^{2} /\right.$ year $)$} \\
\cline { 2 - 7 } & $2015-2017$ & $2017-2019$ & $2015-2019$ & $2015-2017$ & $2017-2019$ & $2015-2019$ \\
\hline Built-up & -29.783 & 1.919 & -27.864 & -14.892 & 0.960 & -6.966 \\
\hline Non-built-up & 29.783 & -1.919 & 27.864 & 14.892 & -0.960 & 6.966 \\
\hline
\end{tabular}

Table 7. Comparison of area and speed of change in the area of the land cover result of Combination B

\begin{tabular}{ccccccc}
\hline \multirow{2}{*}{ Land Cover } & \multicolumn{3}{c}{ Area Change $\left(\mathrm{km}^{2}\right)$} & \multicolumn{3}{c}{ Speed of area change $\left(\mathrm{km}^{2} /\right.$ year $)$} \\
\cline { 2 - 7 } & $2015-2017$ & $2017-2019$ & $2015-2019$ & $2015-2017$ & $2017-2019$ & $2015-2019$ \\
\hline Built-up & -19.027 & 0.260 & -18.766 & -9.513 & 0.130 & -4.692 \\
\hline Non-built-up & 19.027 & -0.260 & 18.766 & 9.513 & -0.130 & 4.692 \\
\hline
\end{tabular}

Based on the results for both combination A and combination B, there is a significant difference between the two. This difference is caused by the combination of the spectral index that has been applied to combination A and combination B, combination A (UI-NDVI-MNDWI) and combination B (NDBI-NDVI-MNDWI). In combination A by utilizing the UI index using band B12 (SWIR-2) and combination B by utilizing the NDBI index using band B11 (SWIR-1). The capabilities of these two bands, B11 (SWIR-1) and B12 (SWIR-2) can be used in extracting built-up land, but the processing results show that the ability of band B11 (SWIR-1) in combination B appears to produce a larger coverage area of built-up land than combination A.

One of the causes of the difference in the area of built-up land for combination A and combination B is due to the weaknesses of the UI and NDBI spectral indices namely the inability of the UI and NDBI spectral indices to distinguish between built-up land and bare land so that most of the bare land in the surrounding study area is mixed with built-up land. Built-up land and bare land reflect more SWIR waves than NIR, whereas water bodies do not reflect the infrared spectrum. In the case of vegetation, the reflection of the NIR waves is higher than the SWIR spectrum (Sinha et al., 2016).

The spectral indices combination processing using the SWIR-2 band in UI and SWIR-1 in NDBI has different spectral reflectance capabilities. This is the difference parameter from the use of each UI and NDBI in combination A and combination B. The difference in the spectral ability of the two bands to reflect reflectance 
values to the Sentinel-2 image sensor is influenced by the characteristics of each band. The B11 (SWIR-1) band has a center wavelength of $1610 \mathrm{~nm}$ otherwise, the B12 (SWIR-2) band has a center wavelength of 2190 $\mathrm{nm}$. This means B12 (SWIR-2) band reflects more reflectance than B11 (SWIR-1) band so that on the Sentinel2 satellite image sensor, pixel data is identified as built-up land and bare land larger in the study area (Kawamura et al., 1996; Zha et al., 2003). However, the change in the area of built-up land in the two combinations shows the same pattern, namely a decrease in the area of built-up land in the 2015 to 2017 period and an increase in the built-up land area in the 2017 to 2019 period.

\section{Conclusions}

Based on the result of this study, it can be concluded that both combination A and combination B have OA (overall accuracy) values above $80 \%$ and the Kappa coefficient values are included in the medium to high category. The spectral indices combination shows bare land is identified as the built-up object and may differentiate vegetation and water bodies as non-built-up objects. The pattern of the urban built-up land direction shows a tilt toward the west and east side of the city of Surabaya with the most dominant built-up land concentration in the center of Surabaya City and extends to the outskirts of the city borders. The speed of change shows that there are a decreasing number of built-up land from 2015 to 2017 and an increasing number of built-up land from 2017 to 2019. Overall, combination A and combination B can identify built-up land in Surabaya, but it still has a lack that it can't able to identified bare land properly as a different object. Further study needs to be accomplished to solve this problem in the future by combining more methods.

\section{Acknowledgment}

We would like to thank the Department of Geomatic Engineering ITS for giving the authors a chance to publish this study in their journal, ESRI Indonesia for giving the ArcGIS student-license to process the data, and ESA for providing the free Sentinel-2 imagery data source and SNAP software to process remotely sensed data.

\section{References}

Bashit, N., Prasetyo, Y., \& Sukmono, A. (2020). Analysis of Built-up Land Spatial Patterns Using Multitemporal Satellite Imagery in Pekalongan City. Journal of Applied Geospatial Information, 4(2), 356-362. https://doi.org/10.30871/jagi.v4i2.2014

Congalton, R. G., \& Green, K. (2009). Assessing the Accuracy of Remotely Sensed Data: Principles and Practices. (2nd Edition). Lewis Publishers. https://doi.org/https://doi.org/10.1201/9781420055139

Greensted, A. (2010). Image Processing: http://www.labbookpages.co.uk/software/imgProc/otsuThreshold.\%0Ahtml

Indriastuti, M., Hani'ah, \& Sukmono, A. (2018). Analisis Kepadatan Bangunan Menggunakan Interpretasi Hibrida Citra Satelit Landsat Di Kecamatan Ungaran Timur Dan Ungaran Barat Kabupaten Semarang Tahun 2009-2018. Jurnal Geodesi Undip, 7(4), 167-175.

Izza, A. S., Pribadi, C. B., \& Budisusanto, Y. (2020). Analisis Kesesuaian Kawasan Terbangun Dengan Rencana Tata Ruang Wilayah Di Kawasan Sempadan Pantai Kabupaten Rembang. Geoid, 16(1), 1-7. https://doi.org/10.12962/j24423998.v16i1.7972

Kawamura, P., Jayamanna, S., \& Tsujiko, Y. (1996). Relation Between Social And Environmental Conditions In Colombia, Sri Lanka And The Urban Index Estimated By Satellite Remote Sensing Data. International Archives of Photogrammetry and Remote Sensing, XXXI(B7), 321-326.

KPUPR. (2017). Panduan Praktis Implementasi Agenda Baru Perkotaan Untuk Kota Berkelanjutan di Indonesia.

Otsu, N. (1979). A Threshold Selection Method from Gray-Level Histograms. IEEE Transactions on Systems, Man and Cybernetics, 20(1), 62-66.

Prasomsup, W., Piyatadsananon, P., Aunphoklang, W., \& Boonrang, A. (2020). Extraction technic for built-up area classification in Landsat 8 imagery. International Journal of Environmental Science and Development, 11(1), 1520. https://doi.org/10.18178/ijesd.2020.11.1.1219

Puspitasari, S., \& Suharyadi. (2016). Kajian Kepadatan Bangunan Menggunakan Interpretasi Hibrida Citra Landsat-8 OLI di Kota Semarang Tahun 2015. Jurnal Bumi Indonesia, 5, 1-9.

Sinha, P., Verma, N. K., \& Atumo, E. A. (2016). Urban Built-up Area Extraction and Change Detection of Adama Municipal Area using Time-Series Landsat Images. August. https://doi.org/10.23953/cloud.ijarsg.67

XI, Y., Thinh, N. X., \& LI, C. (2019). Preliminary comparative assessment of various spectral indices for built-up land 
derived from Landsat-8 OLI and Sentinel-2A MSI imageries. European Journal of Remote Sensing, 52(1), 240252. https://doi.org/10.1080/22797254.2019.1584737

Zha, Y., Gao, J., \& Ni, S. (2003). Use of Normalized Difference Built-up Index in Automatically Mapping Urban Areas from TM Imagery. International Journal of Remote Sensing, 24(3), 583-594. https://doi.org/10.1080/01431160304987 